\section{Original Research}

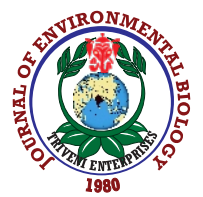

DOI : http://doi.org/10.22438/jeb/41/5/MRN-1250
Journal Home page : www.jeb.co.in $\star$ E-mail : editor@jeb.co.in Journal of Environmental Biology

p-ISSN: 0254-8704 e-ISSN: 2394-0379 CODEN: JEBIDP

\title{
Potential use of plant colonizing Pantoea as generic plant growth promoting bacteria for cereal crops
}

\author{
A. Suman*, L. Shukla, P.S. Marag, P. Verma, S. Gond and J. Sai Prasad \\ Division of Microbiology, ICAR-Indian Agricultural Research Institute, New Delhi-110 012, India \\ *Corresponding Author Email : archsuman@gmail.com
}

\section{Abstract}

Aim: To investigate Pantoea isolates for multifarious plant growth promoting activities, their phylogenetic positioning and inoculation impact on plant growth of cereal crops to develop as generic PGP biofertilizer for different crops

Methodology: Eight Pantoea sp. isolated from wheat and maize growing in different agro-climatic conditions were used for studying cultural characteristics ( $\mathrm{pH}$, Salt and Temp tolerance) PGP traits (nutrient solubilization, siderophore, IAA and hydrolytic enzyme production) and 16SrRNAgene phylogenetic analysis. In vivo evaluation of Pantoea inoculants was studied with 3 cereal test crops in pot house studies.

Results: Pantoea isolates identified through 16S rRNA gene sequencing viz. Pantoea cyperipedii, Pantoea dispersa, Pantoea sp. (endophytes) from maize and Pantoea agglomerans, Pantoea ananatis (rhizospheric), Pantoea eucalypti, Pantoea sp., and Pantoea dispersa (endophytes) from wheat, possessed major and micronutrient solubilization activities with solubilization Index for $\mathrm{P}(\mathrm{PSI}), \mathrm{K}(\mathrm{KSI})$ and $\mathrm{Zn}(\mathrm{ZSI})$ varied from 2.7 to $5.3,0$ to 5.3 and 3.7 to 6.0 , respectively. Production of siderophore (SPI) and IAA varied from 3.3 to 5.7 and 9.0 to $131.8 \mu \mathrm{g} \mathrm{mg}{ }^{-1}$ proteins. Isolates of $P$ dispersa and $P$ agglomerans possessed extracellular activities of hydrolytic enzymes cellulase, amylase, lipase and protease. The inoculation effect of Pantoea isolates in pot house studies indicated positive influence on plant growth of maize, wheat and rice crops.

Interpretation: Pantoea isolates, due to their plant growth improving capabilities and wide colonization capabilities, may be used for preparing a new safe biofertilizer.

Key Words: Bioinoculants, Endophytes, Nutrient solubilization, Pantoea, PGPB

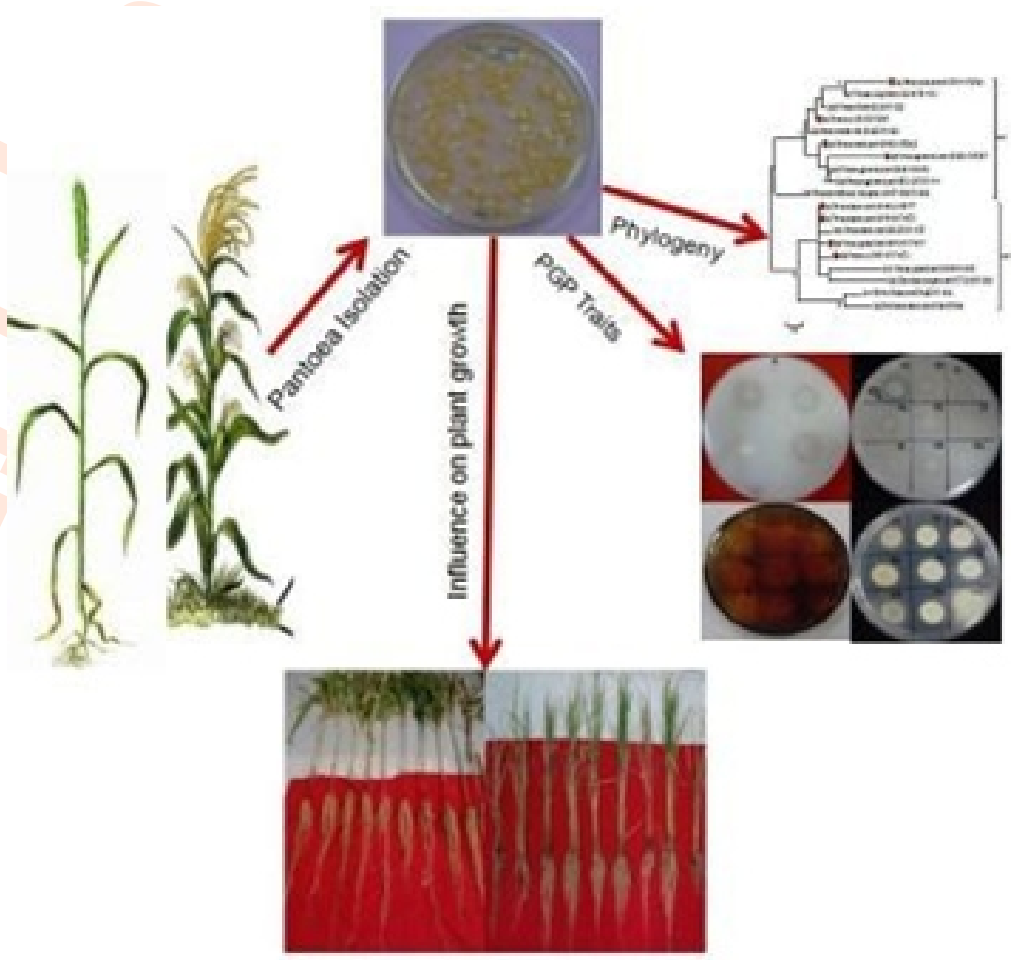

How to cite : Suman, A., L. Shukla, P.S. Marag, P. Verma, S. Gond and J. Sai Prasad: Potential use of plant colonizing Pantoea as generic plant growth promoting bacteria for cereal crops. J. Environ. Biol., 41, 987-994 (2020). 


\section{Introduction}

Beneficial effects of plant associated bacterial communities have been well recognized in natural and managed ecosystems for their important roles in supporting plant health, growth and productivity. Compant et al. (2016) described endophytes as neutral, commensal, beneficial and dormant saprobe microflora that can be isolated from different plant tissues not showing any visible symptoms. Endophytic microflora develops microbial communities in close associations within different tissues/organs of plant endosphere ((Chanway, 1996; Suman et al., 2001). These endophytic microorganisms benefit host plant directly by promoting nutrient availability, biological nitrogen fixation, and the production of phytohormones (Adesemoye and Egamberdieva, 2013; Suman et al., 2005). Indirectly, they may act as biological control agents to reduce microbial pathogens, through antibiosis, competition and/or systemic resistance induction (Lugtenberg and Kamilova, 2009).

The members of Enterobacteriaceae (Gamma proteo bacteria) are frequent colonizers of plant endo- and rhizosphere of grasses and other crops (Coleman-Derr et al., 2016). The bacterial genus Pantoea, comprises many versatile species that have been isolated from a multitude of environments. These have been reported as rhizospheric and endophytic colonizers of corn and wheat plant, potato stems, rice seeds and citrus leaves. Several studies have reported the potential of Pantoea spp. as plant growth promoter by solubilizing phosphorus, stimulating phytohormone production, induction of systemic resistance and protection against pests and plant-pathogenic microorganisms (Sergeeva et al., 2007; Dastager et al., 2009). Pantoea group being a ubiquitous and versatile group of genetic tractability is apt for exploring niche-specific adaptation and opportunism. These are also being explored for the development of agricultural, medical and environmental products (Walterson and Stavrinides, 2015).

Identification of new plant growth promoting bacterial strains having abilities of wider adaptation to colonize different crops is gaining importance in sustainable agriculture and their commercial applications as microbial technologies for improved and profitable agriculture is expanding quite rapidly (Backer et al., 2018).

Therefore, the present study was planned to investigate diverse Pantoea isolates for multifarious plant growth promoting activities and their inoculation effect on plant growth of different graminaceous crops.

\section{Materials and Methods}

Pantoea isolates, Phylogenetic analysis and Cultural characteristics : Eight Pantoea sp. isolated from wheat and maize growing in different agro-climatic conditions were used in the present study (Table 1) Isolates were cultured and maintained on nutrient agar growth medium. The sequences of $16 \mathrm{~S}$ rRNA gene of Pantoea isolates (present study) and eleven of different species of Pantoea downloaded from NCBI GenBank database as reference for phylogenetic analysis were used to construct a phylogenetic tree. Sequences of Erwinia tasmaniensis, Erwinia billingiae and Enterobacter aerogenes were used as outgroups for phylogenetic analysis. The evolutionary history was inferred by using the Maximum Likelihood method, based on the TamuraNei model and the tree with the highest log likelihood as conducted in MEGA7 software. Pantoea isolates were screened by plate spot assay $\left(10 \mu \mathrm{l} \approx 10^{3}\right.$ cells) on nutrient agar plates for temperature tolerance by incubation at temperature ranging from 4 to $40{ }^{\circ} \mathrm{C}$ for $72-96 \mathrm{~h}$. For $\mathrm{pH}$ tolerance, nutrient agar with $\mathrm{pH}$ ranging from 3 to 11 with an increment of one was plate spotted and incubated at $30^{\circ} \mathrm{C}$ for $72-96 \mathrm{hrs}$. The isolates were screened for salt tolerance by spot inoculating each Pantoea isolate onto nutrient agar plates supplemented with variable $\mathrm{NaCl}$ concentrations of $5,10,15,20$ and $25 \%$ (w/v) and incubating at $30{ }^{\circ} \mathrm{C}$ for $72 \mathrm{hrs}$. Bacterial growth on spots was considered positive after incubation.

Hydrolase activity of Pantoea isolates : Pantoea isolates were screened qualitatively for extracellular hydrolytic enzyme activities for which $10 \mu \mathrm{l}$ (1) $10^{3}$ cells) suspension of different Pantoea isolates were spotted onto minimal media $(\mathrm{Mm})$ agar plates $\left(0.1 \% \mathrm{NaNO}_{3}, 0.1 \% \mathrm{~K}_{2} \mathrm{HPO}_{4}, 0.05 \% \mathrm{MgSO}_{4}, 0.1 \% \mathrm{KCl}\right.$, $0.05 \%$ yeast extract and $1.5 \%$ Bacto agar) $\mathrm{pH} 7.0$, supplemented

Table 1 : Pantoea isolates from different crop resources

\begin{tabular}{llllll}
\hline Pantoea isolates & Isolate No & Genbank accession & Endophytic/Rhizospheric & Source crop/Variety & Location \\
\hline P. agglomerans & IARI-BHD-15 & KF054874 & Rhizospheric & Wheat-HD1563 & NEPZ \\
P. eucalypti & IARI-DV-11 & KF054839 & Endophytic & Wheat-HD3043 & NWPZ \\
Pantoea sp. & IARI-DV-65 & KF054847 & Endophytic & Wheat-HD2987 & NWPZ \\
P. ananatis & IARI-IHD-30 & KF054905 & Rhizospheric & Wheat-IWP5007 & CZ \\
P. dispersa & IARI-HHS2-3 & KF054777 & Endophytic & Wheat-HS507 & NHZ \\
P.cyperipedi & IARI-PC4-37 & KT149747 & Endophytic & Maize-PC4 & NWPZ \\
Pdispersa & IARI-PC4-49 & KT149750 & Endophytic & Maize-PC4 & NWPZ \\
Pantoeasp. & IARI-PC4-87 & KT149752 & Endophytic & Maize-PC4 & NWPZ \\
\hline
\end{tabular}

NEPZ: North Eastern Plain Zone of India; NWPZ: North Western Plain Zone of India; CZ: Central Zone of India; NHZ: North Hill Zone of India 
with appropriate substrate for extracellular hydrolytic enzyme detection. For estimation of cellulase activity minimal medium was supplemented with $1 \% \mathrm{CMC}(\mathrm{w} / \mathrm{v})$ and after incubation at $30^{\circ} \mathrm{C}$ for $72 \mathrm{hrs}$, CMCase activity was detected by staining the plates using $0.2 \%$ Congo red for $15 \mathrm{~min}$ and then de-stained by washing twice with $1 \mathrm{M} \mathrm{NaCl}$ for $15 \mathrm{~min}$ for measuring the zone of clearance around the bacterial colony (Teather and Wood, 1982). For amylolytic activity, minimal medium was supplemented with $1 \%$ soluble starch (w/v) and after incubation for $72 \mathrm{hrs}$ at $30^{\circ} \mathrm{C}$, iodine solution was flooded in the plates for zone of clearance (Hankin and Anagnostakis 1975). Minimal media plates containing $1 \%$ gelatine $(\mathrm{w} / \mathrm{v})$ were used for proteolytic activity of the isolates as produced zone of clearance around protease producing bacteria (Nigam and Singh, 1995). Similarly, lipase activity of the Pantoea isolates was screened on tributyrin minimal media plates containing $1 \%(\mathrm{v} / \mathrm{v})$ tributyrin.

Plant growth promoting attributes of Pantoea isolates : Pantoea isolates were screened qualitatively for plant growth promoting attributes by estimation of solubilization of nutrients (phosphorus, potassium and zinc) and production of phytohormone indole-3-acetic acid and siderophores. Spot plate assays were conducted for phosphorous solubilization using Pikovskaya agar medium supplemented with $0.5 \%$ tricalcium phosphate (Pikovskaya, 1948), Aleksandrov medium supplemented with $0.2 \%$ potassium aluminosilicate for potassium solubilization (Hu et al., 2006) and $0.1 \%$ insoluble zinc compound $\mathrm{ZnO}$ for $\mathrm{Zn}$ solubilization (Fasim et al., 2002). For siderophore production, Chromeazurol 'S' agar (Schwyn and Neilands, 1987) plates were spot inoculated with actively grown culture and analysed for the appearance of orange-halo zones against blue background after $72 \mathrm{hrs}$ of incubation at $28^{\circ} \mathrm{C}$. All assays were done in triplicate. After incubation period, diameter of the bacterial colony, the clearing zone on $\mathrm{P}, \mathrm{K}$ and $\mathrm{Zn}$ plates and orange halo zone on siderophore plates were recorded. IAA production was detected by the modified method of Brick et al. (1991) using Salkowski reagent.
Plant growth promotion assay : Effect of Pantoea isolates on the growth parameters of 3 crops viz. maize (PEHM5), wheat (HD2967) and rice (P1121) was studied in three pot experiments in a net house located at Division of Microbiology, Indian Agricultural Research Institute, New Delhi, during respective weather conditions. Seeds treated with Pantoea culture suspension were used. There were 10 treatments that included 8 Pantoea inoculants, positive control (recommended dose of nitrogen, phosphorous and potassium (NPK)) and negative control (no recommended NPK and bacterial inoculants) and were replicated 3 times. Pots were completely randomized and $60-70 \%$ available soil moisture was maintained throughout the growth cycle by watering pots as and when required. At two month stage each pot was washed carefully with running water to take out plants with intact root system. Plant growth promotion was evaluated by measuring plant shoot and root length and their fresh weight. A portion of washed shoot and root was dried in the oven at $80^{\circ} \mathrm{C}$ for $96 \mathrm{hrs}$ to record dry weights.

Statistical analyses : Plant biometric data was subjected to analysis of variance with one way classification to find treatment differences and interaction effects $(p=0.05)$ (Snedecor and Cochran, 1967). Correlation among Pantoea PGP traits and their influence on plant biometric parameters was drawn using MS Excel DataAnalysis.

\section{Results and Discussion}

Use of beneficial microbial inoculants for plants is a promising partial alternative for hazardous chemical fertilizers. Genus Pantoea are highly adaptive for colonization in different hosts due to its ability to utilize diverse compounds. Nearly, 20 species of Pantoea have been isolated from diverse hosts over last few years (Walterson and Stavrinides, 2015). Most of the early research on Pantoea has focused on their parasitic association with plant hosts, but lately their potential role as plant growth promoter is realized and are being researched more and more. In this study, 8 Pantoea isolates from rhizo-endosphere of diverse ecotypes of wheat and maize plants were identified using

Table 2 : Cultural characteristics and PGP indicators of Pantoea isolates

\begin{tabular}{|c|c|c|c|c|c|c|c|c|c|}
\hline \multirow[t]{2}{*}{ Pantoea Isolates } & \multicolumn{3}{|c|}{ Cultural characteristics } & \multirow[b]{2}{*}{$\mathrm{pH}$} & \multicolumn{4}{|c|}{ PGP index } & \multirow[b]{2}{*}{ IAA } \\
\hline & Colour & $\operatorname{Temp}\left({ }^{\circ} \mathrm{C}\right)$ & $\mathrm{NaCl}(\%)$ & & PSI & KSI & $\mathrm{ZnSI}$ & SPI & \\
\hline P. agglomerans & Cream & $4-30$ & 5 & $7-10$ & 4.3 & 5.0 & 6.2 & 5.8 & 131.8 \\
\hline P. eucalypti & Cream & $20-40$ & 5 & $3-6$ & 5.3 & 4.7 & 4.3 & 4.7 & 91.7 \\
\hline Pantoea sp. & White & $10-30$ & 5 & $5-6$ & 2.7 & - & 3.7 & 3.3 & 64.7 \\
\hline P. ananatis & Cream & $4-30$ & 5 & $5-8$ & 4.0 & 5.3 & 4.3 & 4.7 & 44.8 \\
\hline P. dispersa & Yellow & $10-30$ & 15 & $3-7$ & 5.3 & 3.0 & 5.3 & 5.0 & 78.6 \\
\hline P.cyperipedi & Yellow & $10-30$ & 5 & $5-7$ & 5.0 & 4.0 & 6.0 & 5.0 & 9.0 \\
\hline Pdispersa & Yellow & $20-30$ & 5 & $4-8$ & 4.3 & 4.3 & 5.0 & 4.7 & 86.4 \\
\hline Pantoea sp. & Yellow & $10-30$ & 5 & $3-7$ & 5.3 & 5.0 & 6.0 & 5.3 & 83.3 \\
\hline
\end{tabular}

Solubilization Index for Phosphorous (PSI), Potassium (KSI), Zinc (ZnSI) and Production Index for Siderphore (SPI) calculated as (colony diameter + solubilization zone)/Colony diameter. Indole Acetic Acid (IAA): $\mathrm{\mu g} \mathrm{mg}^{-1}$ protein 
16SrRNA gene as Pantoea cyperipedii, Pantoea dispersa, Pantoea sp. (endophytes) from maize and Pantoea agglomerans, Pantoea ananatis (rhizospheric), Pantoea eucalypti, Pantoea sp., and Pantoea dispersa (endophytes) from wheat plants. On phylogenetic analysis, all isolates were grouped in two major clades. Clade I had five species of Pantoea viz; $P$. eucalypti, $P$. allii, $P$. ananatis, $P$. agglomerans and $P$. stewartii. The isolate number IARI-DV-65 was close to Pantoea allii, and IARIPC4-87 was identified as Pantoea cypripedii. Clade II have $P$. dispersa, P. cypripedii and outgroup isolates. Brady et al. (2008) evaluated multi locus sequence analysis (MLSA) using four housekeeping genes, gyrB, rpoB, atpD and infB as a means for rapid classification and identification of $P$ antoea strains.

Different Pantoea isolates exhibited white to yellowish circular colonies of 2-3 mm diameter on nutrient agar medium plates at $30^{\circ} \mathrm{C}$ incubation. Probably owing to their isolation from the host growing in different environmental conditions, these isolates possessed variable cultural characteristics as they could grow on variable $\mathrm{pH}$, temperature and salt levels (Table 2). Similar reports indicate that cold tolerant $P$. dispersa and $P$. agglomerans isolated from soils of Himalaya could grow from $4^{\circ}$ to $42^{\circ} \mathrm{C}$ with maximal growth at $30^{\circ} \mathrm{C}$, at $\mathrm{pH} 3-10$ and at $\mathrm{NaCl}$ concentrations up to $8 \%$ (Selvakar et al., 2008; Gupta and Vakhlu, 2015). After rhizosphere and rhizoplane colonization, some microorganisms enter roots and establish as endophytic microorganisms through passive diffusion from cracks and root tips and by secreting cellwall degrading enzymes (Hallman et al., 2001, Lodewyckx et al., 2002, Krause et al., 2006). In the tested Pantoea isolates, good cellulase activity and moderate activities of amylase, lipase and protease enzymes were present. $P$. dispersa and $P$. agglomerans possessed all 4 tested hydrolytic enzymes (Table 3 ). The

Table 3 : Extracellular Hydrolytic Activities of Pantoea isolates

\begin{tabular}{lllll}
\hline Pantoea lsolates & \multicolumn{5}{c}{ Hydrolytic Enzyme Production } \\
\cline { 2 - 5 } & Cellulase & Amylase & Lipase & Protease \\
\hline P. agglomerans & ++ & + & - & + \\
P. eucalypti & + & + & + & - \\
Pantoea sp. & - & + & - & + \\
P. ananatis & +++ & - & + & + \\
P. dispersa & + & + & + & + \\
P.cyperipedi & + & + & - & + \\
Pdispersa & ++ & + & + & + \\
Pantoea sp. & + & - & + & + \\
\hline
\end{tabular}

-, no activity; +, moderate activity; ++, high activity; +++, very high activity

Table 4 : Correlation among bacterial PGP traits and plant biometric parameters

\begin{tabular}{lccccc}
\hline & $P S I$ & KSI & ZnSI & SPI & IAA \\
\hline PSI & 1.00 & & & & \\
KSI & 0.62 & 1.00 & & & \\
ZnSI & 0.58 & 0.51 & 1.00 & 1.00 & 1.00 \\
SPI & 0.69 & 0.81 & 0.86 & 0.35 & -0.43 \\
IAA & 0.04 & 0.18 & 0.15 & -0.05 & -0.36 \\
MSL & 0.22 & -0.47 & 0.16 & 0.40 & -0.11 \\
MRL & 0.16 & 0.48 & 0.43 & 0.76 & -0.49 \\
MSW & 0.56 & 0.42 & 0.93 & -0.18 & -0.49 \\
MRW & 0.11 & -0.49 & 0.29 & -0.13 & -0.52 \\
RSL & -0.35 & -0.38 & -0.41 & -0.35 & 0.23 \\
RRL & 0.11 & -0.02 & -0.19 & 0.32 & 0.52 \\
RSW & -0.25 & -0.24 & -0.29 & 0.54 & 0.08 \\
RRW & -0.18 & 0.39 & 0.08 & 0.58 & 0.30 \\
WSL & 0.19 & 0.13 & 0.64 & 0.37 & 0.27 \\
WRL & 0.15 & 0.27 & 0.67 & 0.55 & \\
WSW & 0.11 & -0.06 & 0.59 & 0.59 & \\
WRW & 0.29 & 0.41 & & & \\
\hline
\end{tabular}

Solubilization Index for Phosphorous (PSI), Potassium (KSI), Zinc (ZnSI) and Production Index for Siderophore (SPI), Maize shoot length (MSL), root length (MRL) shoot weight (MSW), root weight (MRW); Rice shoot length (RSL), root length (RRL) shoot weight (RSW), root weight (RRW); Wheat shoot length (WSL), root length (WRL) shoot weight (WSW), root weight (WRW) 


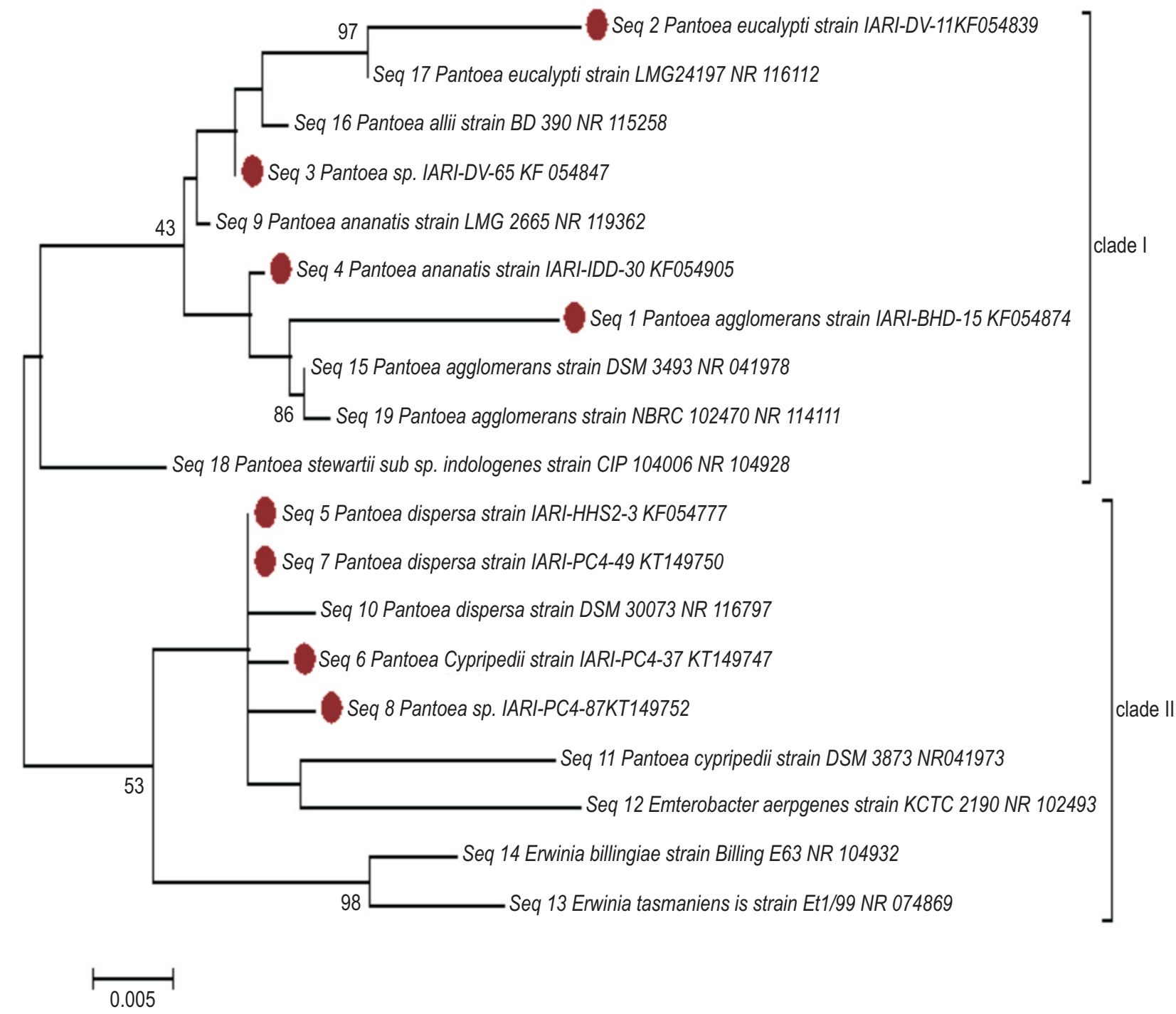

Fig. 1 : Phylogenetic analysis of Pantoea isolates

hydrolytic enzyme complex of amylase, protease, lipase, phosphatase and gelatinase produced extracellularly play a crucial role in mineralization of nutrients by hydrolyzing complex organic matter. NabiJatt et al. (2015) had reported a link between QS signals and extracellular hydrolytic enzymes in P.ananatis isolated from marine environment.

All Pantoea isolates showed variable magnitude of plant growth promoting attributes for 3 types of indicators viz. solubilization of different nutrients, production of siderophore and phytohormones IAA (Table 2). Among plant growth promotion indices, PSI was positively correlated with $\mathrm{KSI}, \mathrm{ZnSI}$ and SPI (Table 4). Earlier many PGP strains from Pantoea have been reported for $\mathrm{P}$ solubilization and phytohormones production (Sergeeva et al., 2007; Dastager et al., 2009). Reports about K solubilization by Pantoea are meagre. Zang and Kong (2014) isolated $\mathrm{K}$ solubilizing bacteria from tobacco rhizosphere; wherein, majority were members of enterobacteriaceae. To the best of our information, $\mathrm{Zn}$ solubilization by Pantoea has been reported for the first time in this study, as all isolates were solubilizing $\mathrm{Zn}$. Functional expression of these plant growth promoting traits along with several others make Pantoea a competent bacteria for colonization in diverse hosts.

The beneficial effect of these Pantoea isolates was assessed in planta with maize, wheat and rice crops. Pantoea inoculated maize plant shoot length varied between 112 to $146 \mathrm{~cm}$ with overall average of $130.5 \mathrm{~cm}$ compared to 124 and $92 \mathrm{~cm}$ in positive control and negative treatments, with improvement of 5 and $41.8 \%$, respectively (Fig 2). The improvement was highest in $P$. agglomerans and $P$. sp. and minimum in $P$. ananatis and $P$. dispersa. Shoot fresh weight was at par with positive control but 

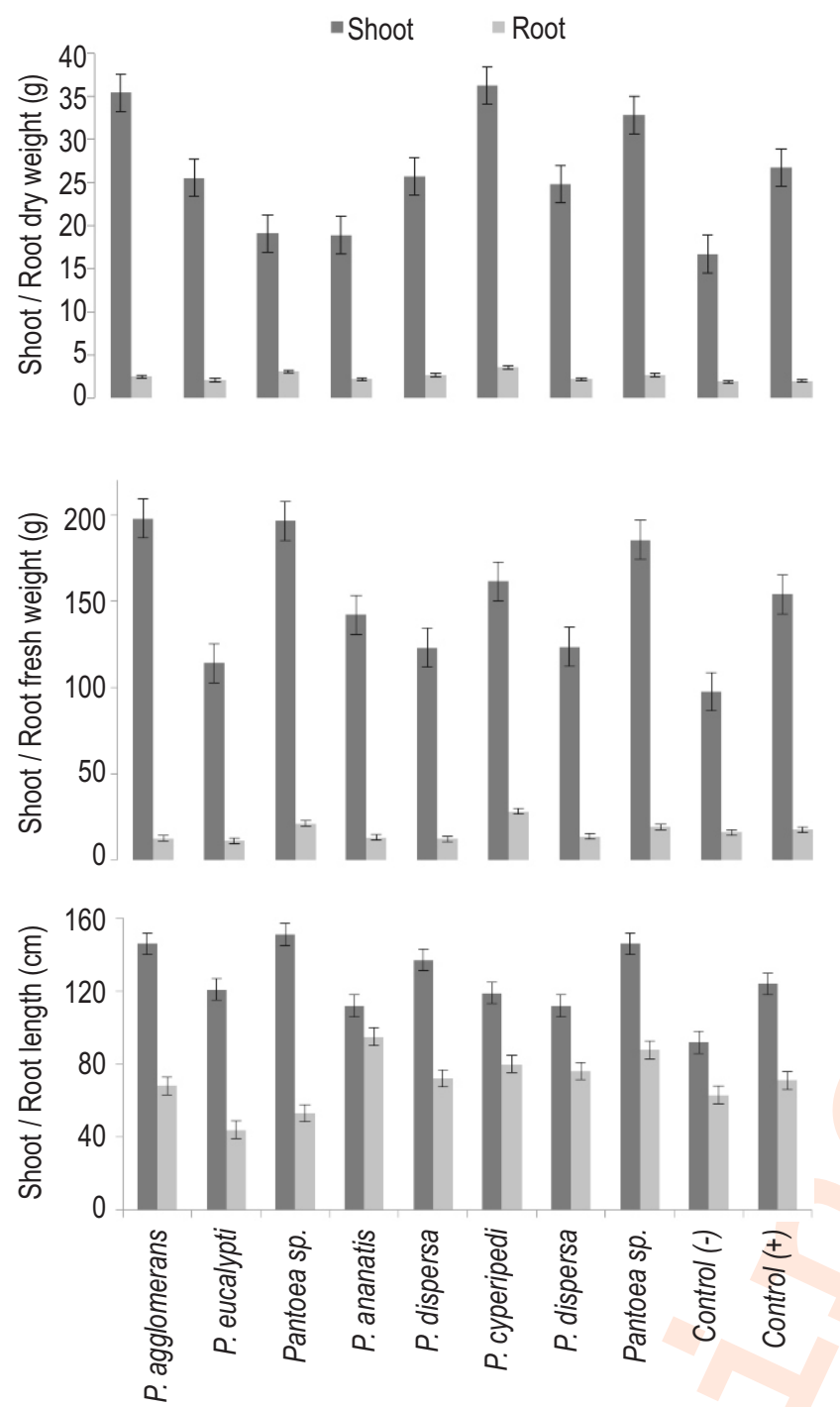

Fig. 2 : Effect of Pantoea isolates on maize plant biometric parameters.

was $59 \%$ more than negative control treatment. Similar reflection was observed in shoot dry weight as it was at par with positive control but was $63.5 \%$ higher than negative control treatment. Pantoea inoculated plant roots varied from 44 to $95 \mathrm{~cm}$ with mean length of $72 \mathrm{~cm}$ which was at par with positive control treatment $(71 \mathrm{~cm})$ and $14.3 \%$ more than negative control $(63 \mathrm{~cm})$ treatment. Similarly root fresh and dry weight was 2.8 and $38 \%$ higher than both the respective control treatments.

In rice plant assay, overall effect of Pantoea isolates on shoot length was at par with positive control treatment and 29.8\% higher than the negative control treatment (Fig 3). Individually, each Pantoea isolate improved shoot length above negative control by 8.8 to $45.6 \%$ with highest in Pantoea sp followed by $P$ ananatis and $P$ cyperipedi. Pantoea inoculation improved shoot fresh weight by 44 and $80.9 \%$ as compared to positive and negative control, respectively, with highest in Pantoea sp and $P$
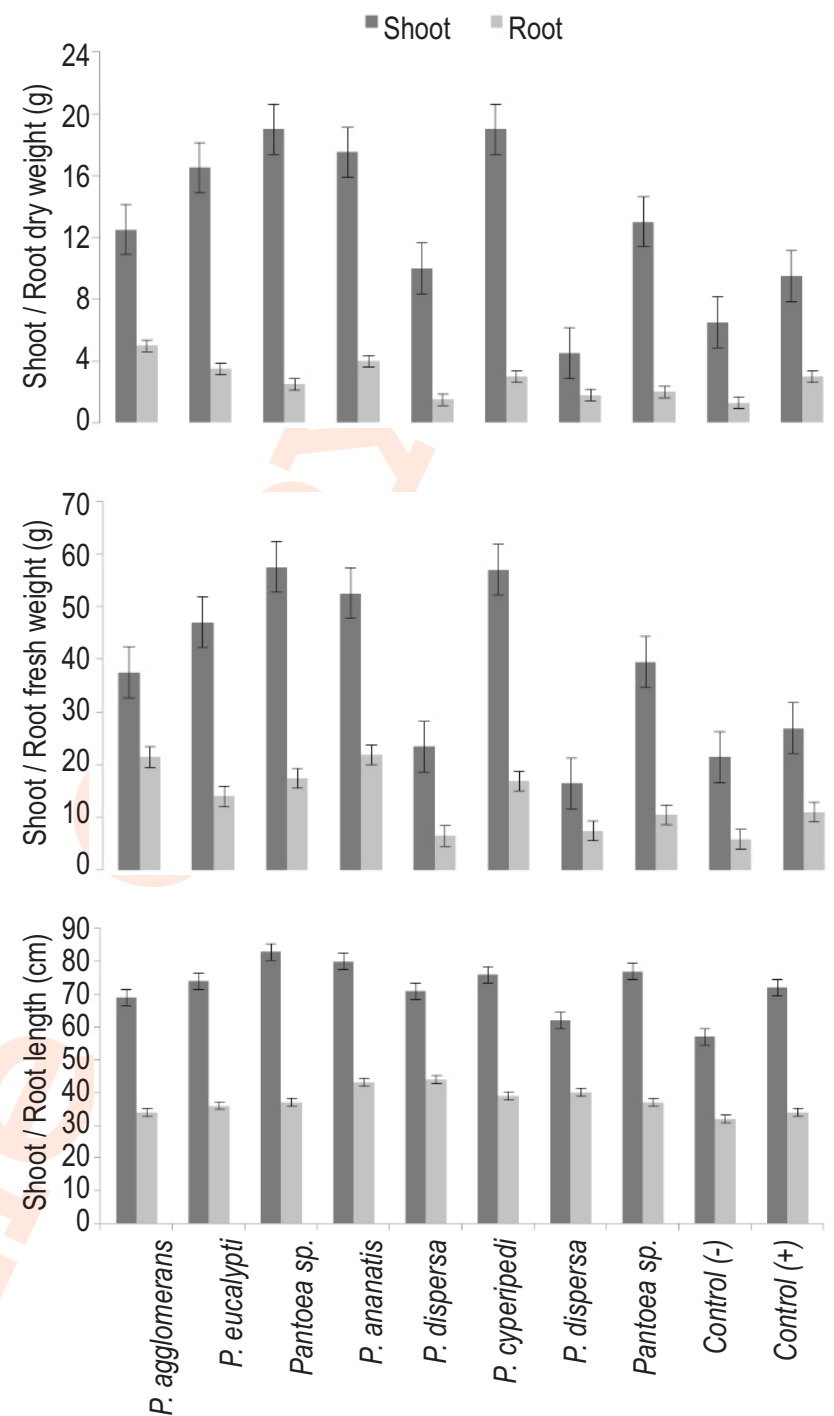

Fig. 3 : Effect of Pantoea isolates on rice plant biometric parameters.

cyperipedi . Similar trend was recorded in shoot dry weight also. Root length was almost at par in both control treatments but in negative control, roots were very fragile and fresh weight was near half of the positive control treatment. Pantoea inoculation improved root length by $21 \%$ and fresh weight by $39.6 \%$ as compared to negative control, whereas, these were 14 and $26 \%$ more as compared to positive control treatment.

Pantoea inoculated wheat shoot and root length was at par with positive control but was 46.8 and $62 \%$ more as compared to negatively control, respectively (Fig. 4). Shoot fresh weight due to Pantoea inoculation was 6.5 and $145 \%$ more than positive and negative control, respectively. Similarly root fresh weight increased by 27 and $50 \%$ compared with both controls, respectively. Individually all plant biometric parameters were better due to Pantoea inoculation with highest shoot length in $P$. agglomerans and lowest in $P$. annanatis and $P$. eucalypti. The 


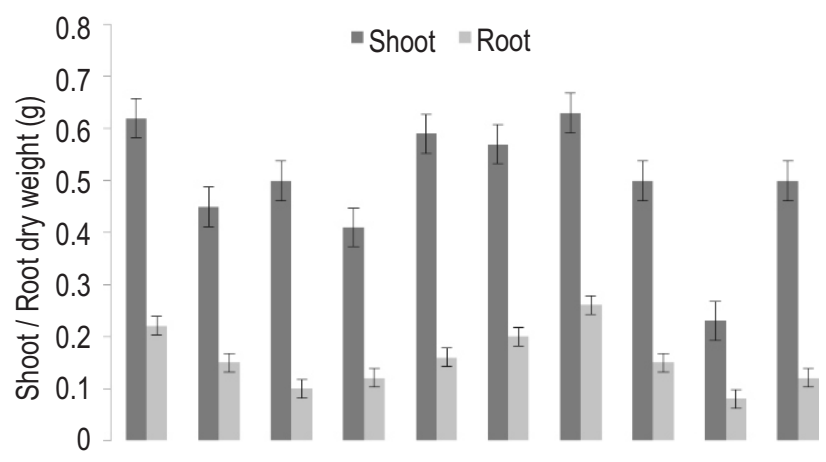

isolate on wheat growth at low temperatures. Mishra et al. (2011) demonstrated the positive effect of $P$. agglomerans strain for improving maize and chickpea growth. The promotion of sugarcane growth by the endophytic Pantoea agglomerans strain 33.1 was studied under gnotobiotic and greenhouse conditions using the green fluorescent protein (GFP)-tag (Quecine et al., 2012). Khalimi et al. (2012) has demonstrated the positive influence of combined inoculation of two isolates of $P$. agglomerans isolated from groundnut rhizosphere on the growth and yield of rice crop. Kim et al. (2012) have successfully demonstrated the high endophytic colonization of $P$. annanatis in different tissues of pepper and growth promotion in the pepper plantations. Singh et al. (2014) have reported P. cypripeddi in consortium with Enterobacter aerogens and Rhizobium ciceri for enhancing the performance of chickpea crop. Cherif-Silini et al. (2019) reported that Pantoea agglomerans strain Pa induced stress tolerance in durum wheat and strongly promoted this as an efficient biofertilizer for wheat plants in arid and salinity-impacted regions.

Pantoea isolates, owing to their diverse colonization capabilities and abilities to function in phosphate, potash and zinc solubilization, siderophore and IAA production, belong to a class of generic plant growth promoting bacteria (PGPB), which can promote growth of several plant species. Since these PGPB inoculants exhibited multiple traits beneficial to the host plants at lower chemical inputs, they may be applied for preparing a new, safe, and effective product for partial replacement of chemical fertilizer.

\section{Acknowledgments}

Authors acknowledge financial and general support of ICAR-IARI through institute project (Code-IXX11843) on "Integrated crop and resource management for enhanced productivity and profitability". Authors also acknowledge personal assistance of Dr. Ram Nageena. Authors do not have any competing interests in the MS.

\section{References}

Fig. 4 : Effect of Pantoea isolates on wheat plant biometric parameters.

shoot fresh weight was highest in P. agglomerans and P.dispersa (195\%) and lowest in $P$. annanatis (75\%) compared to positive control. Similar trend was observed in root dry weight also.

On correlating plant growth promoting indices of Pantoea isolates with plant biometric parameters of maize, rice and wheat, PSI and ZNSI were positively correlated with maize and wheat parameters, but overall poor correlation was observed with rice (Table 4).

Plant growth promoting abilities of Pantoea sp. has been reported for different crops. Selvakumar et al. (2008) have demonstrated the beneficial effect of a cold tolerant P.dispersa

Adesemoye, A.O. and D. Egamberdieva: Beneficial effects of plant growth promoting rhizobacteria on improved crop production: Prospects for developing economies. In: Bacteria in Agrobiology: Crop Productivity, Springer Berlin Heidelberg, pp. 45-63 (2013).

Backer, R., J.S. Rokem, G. llangumaran, J. Lamont, D. Praslickova, E. Ricci, S. Subramanian and D.L. Smith: Plant growth-promoting rhizobacteria: Context, mechanisms of action, and roadmap to commercialization of biostimulants for sustainable agriculture. Front. Plant Sci., 9, 1473 (2018).

Brady, C., I. Cleenwerck, S. Venter, M. Vancanneyt, J. Swings and T. Coutinho: Phylogeny and identification of Pantoea species associated with plants, humans and the natural environment based on multilocus sequence analysis (MLSA). Syst. Appl. Microbiol., 31, 447-460 (2008).

Brick, J.M., R.M. Bostock and S.E. Silverstone: Rapid in-situ assay for 
indole acetic acid production by bacteria immobilized on nitrocellulose membrane. Appl. Environ. Microbiol., 57, 535-538 (1991).

Chanway, C.P.: Endophytes they're not just fungi! Can. J. Bot., 74, 321$322(1996)$

Cherif-Silini, H., B. Thissera, A.C. Bouket, N. Saadaoui, A. Silini, M. Eshelli, F.N. Alenezi, A. Vallat, L. Luptakova, B. Yahiaoui and S. Cherrad: Durum wheat stress tolerance induced by endophyte Pantoea agglomerans with genes contributing to plant functions and secondary metabolite arsenal. Int. J. Mol. Sci, 20, 3989 (2019).

Coleman Derr, D., D. Desgarennes, G.C. Fonseca, S. Gross, S. Clingenpeel, T. Woyke and S.G. Tringe: Plant compartment and biogeography affect microbiome composition in cultivated and native Agave species. New Phytologist, 209, 798-811 (2016).

Compant, S., K. Saikkonen, B. Mitter, A. Campisano and B.J. Mercado: Editorial special issue soil, plants and endophytes. Plant Soil, 405, 1-11 (2016).

Dastager, S.G., C.K. Deepa, S.C. Puneet, C. Nautiyal and S. Pandey: Isolation and characterization of plant growth promoting strain Pantoea NII-186. From Western Ghat forest soil, India. Lett. Appl. Microbiol., 49, 20-25(2009).

Fasim, F., N. Ahmed, R. Parsons and G.M. Gadd: Solubilization of zinc salts by a bacterium isolated from the air environment of a tannery. FEMS Microbiol. Lett., 213, 1-6 (2002).

Gupta, P. and J. Vakhlu: Culturable bacterial diversity and hydrolytic enzymes from drass, a cold desert in India. Afr. J. Microbiol. Res., 9, 1866-1876 (2015).

Hallmann, J., A. Quadt-Hallmann, W.F. Mahaffee and J.W. Kloepper: Bacterial endophytes in agricultural crops. Can. J. Microbiol., 43, 895-914 (1997).

Hankin, L. and S.L. Anagnostakis: The use of solid media for detection of enzyme production by fungi. Mycologia, 67, 597-607 (1975).

$\mathrm{Hu}, \mathrm{X}$., J. Chen and J. Guo: Two phosphate and potassium solubilizing bacteria isolated from Tianmu Mountain, Zhejiang, China. World J. Microbiol. Biotechnol., 22, 983-990 (2006).

Khalimi, K., D.N. Suprapta and Y. Nitta: Effect of Pantoea agglomerans on growth promotion and yield of rice. Agric. Sc. Res. J., 2, 240249 (2012)

Kim, S., W.K. Cho, W. Kim, H.J. Jee and C.S. Park: Growth promotion of pepper plants by Pantoea ananatis B1-9 and its efficient endophytic colonization capacity in plant tissues. Plant Pathol. J., 28, 270-281 (2012).

Krause, A., A. Ramakumar, D. Bartels, F. Battistoni, T. Bekel, J. Boch, M. Böhm, F. Friedrich, T. Hurek, L. Krause and B. Linke: Complete genome of the mutualistic, $\mathrm{N}_{2}$-fixing grass endophyte Azoarcus sp. strain BH72. Nature Biotechnol., 24, 1385-1391(2006).

Lodewyckx, C., J. Vangronsveld, F. Porteous, E.R. Moore, S. Taghavi, M. Mezgeay and D.V. Der Lelie: Endophytic bacteria and their potential applications. Critical Rev. Plant Sci., 21, 583-606 (2002)

Lugtenberg, B. and F. Kamilova: Plant-growth-promoting rhizobacteria. Ann. Rev. Microbiol., 63, 541-556 (2009).

Mishra, A., P.S. Chauhan, V. Chaudhry, M.Tripathi and C.S. Nautiyal: Rhizosphere competent Pantoea agglomerans enhances maize
(Zea mays) and chickpea (Cicer arietinum L.) growth, without altering the rhizosphere functional diversity. Anton. Van Leeuwenhoek, 100, 405-413 (2011).

Nabijatt, A., T. Kaihao, L. Jiwen, Z. Zhang and X.H. Zhang: Quorum sensing in marine snow and its possible influence on production of extracellular hydrolytic enzymes in marine snow bacterium Pantoea ananatis B9. FEMS Microbiol. Ecol., 91, 1-13 (2015).

Nigam, P. and D. Singh: Enzyme and microbial systems involved in starch processing. Enzyme Microbiol. Technol., 17, 770-778 (1995).

Pikovskaya, R.I.: Mobilization of phosphorous in soil in connection with vital activity of some microbial species. Mikrobiologiya, 17, 362370 (1948)

Quecine, M.C., W.L. Araújo, P. Rossetto, A. Ferreira, S. Tsui, P.T. Lacava, M. Mondin, J.L. Azevedo and A.A. Pizzirani-Kleinera: Sugarcane growth promotion by the endophytic bacterium Pantoea agglomerans 33.1. App. Environ. Microbiol., 78, 7511-7518 (2012).

Schwyn, B. and J.B. Neilands: Universal chemical assay for the detection and determination of siderophores. Analytical Biochem., 160, 4756 (1987).

Selvakumar, G., J.S. Kundu, P. Nazim, S. Gupta, A.D. Mishra and P.K. Gupta: Characterization of a cold-tolerant plant growth-promoting bacterium Pantoea dispersa $1 \mathrm{~A}$ isolated from a sub-alpine soil in the North Western Indian Himalayas. World J. Microbiol. Biotechnol., 24, 955-960 (2008).

Sergeeva, E., D.L.M. Hirkala and L.M. Nelson: Production of indole-3acetic acid, aromatic amino acid, amino transferase activities and plant growth promotion by Pantoea agglomerans rhizosphere isolates. Plant Soil, 297, 1-13 (2007).

Singh, O., M.Gupta, V. Mittal, S. Kiran, H. Nayyar, A. Gulati and R. Tewari: Novel phosphate solubilizing bacteria 'Pantoea cypripedii PS1'along with Enterobacter aerogenes PS16 and Rhizobium ciceri enhance the growth of chickpea (Cicer arietinum L.). Plant Growth Regul., 73, 79-89 (2014).

Snedecor, G.W. and W.G. Cochran: Statistical Methods. $6^{\text {th }}$ Edn., The lowa State University (1967).

Suman, A., A.K. Shasany, M. Singh, H.N. Shahi, A. Gaur and S.P.S. Khanuja: Molecular assessment of diversity among endophytic diazotrophs isolated from subtropical Indian sugarcane. World $\mathrm{J}$. Microbiol. Biotechnol., 17, 39-45 (2001).

Suman, A., A. Gaur, A.K. Shrivastava and R.L. Yadav: Improving sugarcane growth and nutrient uptake by inoculating Gluconacetobacter diazotrophicus. Plant Growth Regul., 47, 155$162(2005)$.

Teather, R.M. and P.J. Wood: Use of Congo red-polysaccharide interactions in enumeration and characterization of cellulolytic bacteria from the bovine rumen. Appl. Environ. Microbiol., 43, 777 780 (1982).

Walterson, A.M. and J. Stavrinides: Pantoea: Insights into a highly versatile and diverse genus within the Enterobacteriaceae. FEMS Microbiol. Rev., 39, 968-984 (2015).

Zhang, C. and F. Kong: Isolation and identification of potassiumsolubilizing bacteria from tobacco rhizospheric soil and their effect on tobacco plants. Appl. Soil Ecol., 82, 18-25 (2014). 